\title{
Unusual presentation of schistosomiasis as vulval polyp
}

\section{Case Report}

\author{
S. M. Sahabi ${ }^{1}$, A. F. Rabiu ${ }^{2}$ \\ ${ }^{1}$ Dr. S. M. Sahabi, Department of Histopathology, Usmanu Danfodiyo University Teaching Hospital, Sokoto, ${ }^{2}$ Dr. A. F. \\ Rabiu Department of Obstetrics and Gynaecology, Usmanu Danfodiyo University Teaching Hospital, Sokoto
}

Address for Correspondence: Dr. S. M. Sahabi, Email: smsahabii@gmail.com

\begin{abstract}
Background: Schistosomiasis is a water borne disease caused by Schistosoma. It is the third most devastating tropical disease in the world, being a major source of morbidity and mortality for developing countries. Although the clinical manifestations on the urinary or gastrointestinal tracts are widely known, many clinical health-care professionals are unaware of the genital manifestations which are often ignored or underestimated. Aim: To report a rare clinical manifestation of schistosomiasis in the form of vulval polyp and also to increase its awareness its presentation and management. Case Report: An 11-year old pupil of presented to a peripheral hospital with 5-month history of progressive vulva swelling. She had no history of pain, itching, discharge or bleeding from the site. She had no urinary symptoms. The mass was clinically diagnosed as vulval polyp and surgically removed and sent for histology. She did well post operatively and was discharged to follow up in 2 weeks with the histology result. She was however lost to follow up. The histology results showed a granulomatous inflammation secondary to schistosomiasis. Conclusion: Vulval schistosomiasis though rare should be suspected in a child with vulvo-vaginal swelling. Biopsy should be obtained before definitive treatment is instituted.
\end{abstract}

Keywords: Schsistosomiasis, Vulva, Polyp

\section{Introduction}

Schistosomiasis is a water borne parasitic disease caused by Schistosoma, the digenic trematode found in the blood vessels of man and livestock. Sometimes referred to as bilharzias, bilharziasis, or snail fever, it was discovered by Theodore Bilharz, a German surgeon working in Cairo, who first identified the aetiological agent as Schistosoma haematobium in 1851 [1].

It is the third most devastating tropical disease in the world, being a major source of morbidity and mortality for developing countries [2]. The six species of Schistosoma that cause disease worldwide, include Schistosoma haematobium, S. mansoni, S. japonicum, S. intercalatum, S. mekongi and S. guineensis [3].

More than 207 million people, $85 \%$ of who live in Africa, are infected with schistosomiasis [2], and an estimated 700 million people are at risk of infection in 76 countries where the disease is considered endemic, as their agricultural work, domestic chores, and recreational activities expose them to infested water [2,4]. Globally, 200,000 deaths are attributed to schistosomiasis annually [5].

In a study conducted in 2 districts in Sokoto among primary school pupil aged $7-15$, the result showed the overall prevalence of urinary schistosomiasis (Schistosoma haematobium) was 60.8\% (228 positive cases in 375 samples); and for intestinal schistosomiasis (Schistosoma mansoni) was $2.93 \%$ (11 positive in 375 samples) [3].

Female genital schistosomiasis (FGS) is a frequent complication in women with urinary or systemic schistosomiasis, particularly in geographic areas where the disease is endemic [6].

Schistosoma haematobium is the organism most frequently identified in these cases. Persistent, untreated infections may lead to increased susceptibility to sexually transmitted diseases, or even sterility [6]. We describe a case of FGS involving the vulva of an 11-year old girl.

Manuscript received: $18^{\text {th }}$ June 2017

Reviewed: $24^{\text {th }}$ June 2017

Author Corrected: $30^{\text {th }}$ June 2017

Accepted for Publication: $05^{\text {th }}$ July 2017 


\section{Case Report}

Presentation of case- An 11-year old pupil of presented to a peripheral hospital with 5-month history of progressive vulva swelling. She had no history of pain, itching, discharge or bleeding from the site. She had no urinary symptoms. The mass was clinically diagnosed as vulval polyp; surgically removed and sent for histology.

She did well post operatively and was discharged to follow up in 2 weeks with the histology result. She was however lost to follow up. Microscopic examination revealed viable and calcified eggs of schistosomes in a typical advanced circumscribed granuloma with centrally located eggs, zone of epithelioid cells and outer zone of fibrous connective tissue infiltrated by lymphocytes. The histology result showed a granulomatous inflammation secondary to schistosomiasis.

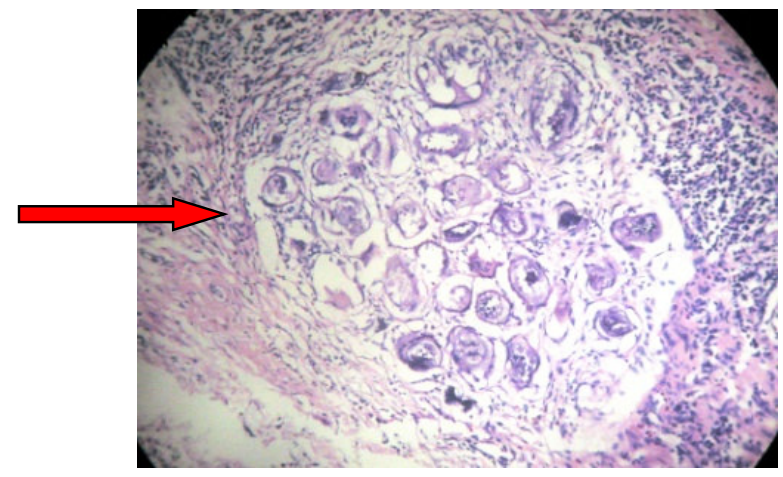

Figure-1: Photomicrograph showing a granuloma with aggregates of ova of S. haematobium (red arrow) (H\&E Mag. X200)

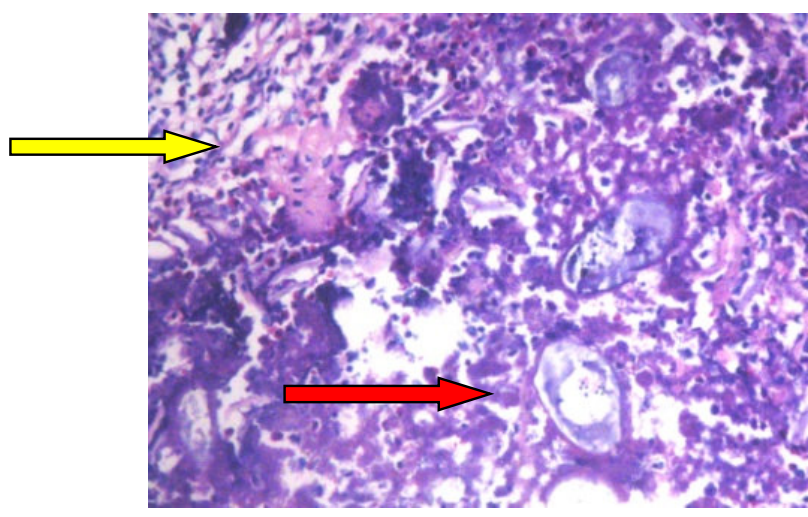

Figure-2: Photomicrograph showing ova of $S$. haematobium (red arrow) in a background with brightly eosinophilic crystalline material (Splendore-Hoeppli phenomenon) [yellow arrow] (H\&E Mag. X400)

\section{Discussion}

Previous studies have also shown that FGS is a common manifestation of $S$. haematobium infection, with a prevalence ranging from 30 to $75 \%$ [3]. It has been estimated that approximately 9 to 13 million women may be afflicted with FGS in Africa alone [3]. Another important patient population to consider is composed of women who have visited endemic areas (especially if they have swum in freshwater lakes), or those who previously resided in those endemic areas [7]. FGS may be an important risk factor in the spread of sexually transmitted diseases including human immunodeficiency virus [8-10], and may lead to infertility secondary to ovarian fibrosis or tubal occlusion $[11,12]$. FGS may indeed be a cofactor for the development of cervical cancer, but a clear link has yet to be established $[13,14]$.

The geographic distribution and etiology of schistosomiasis reflect the unique life cycle of

Obsgyne Review: Journal of Obstetrics and Gynecology
Schistosoma species. Schistosomes infect susceptible freshwater snails in endemic areas, usually with specific species of schistosomes infecting specific species of snails. The infected snails release cercariae 4-6 weeks after infection [15]. They can survive in fresh water up to 72 hours, during which time they must attach to human skin or to that of another susceptible host mammal or die [15].

Successful cercariae attach to human hosts, utilizing oral and ventral suckers. They then migrate through intact skin to dermal veins and, over the next several days, to the pulmonary vasculature. During this migration, the cercariae metamorphose, shedding tails and outer glycocalyces while developing double-lipid-bilayer teguments that are highly resistant to host immune responses [15]. The organisms, now called schistosomula, migrate through the pulmonary capillaries to the systemic 


\section{Case Report}

circulation, which carries them to the portal veins, where they mature in male and female adult worms. Together they migrate along the endothelium, against portal blood flow, to the mesenteric ( $S$ mansoni, $S$ japonicum) or vesicular ( $S$ haematobium) veins, where they begin to produce eggs [15].

The eggs, which are highly antigenic and can induce an intense granulomatous response, migrate through the bowel or bladder wall to be shed via feaces or urine. The cycle starts all over again. Eggs that are not shed successfully may remain in the tissues or be swept back to the portal circulation (from the mesenteric vessels) or to the pulmonary circulation (from the vesicular vessels via the inferior vena cava). Eggs can end up in the skin, brain, muscle, adrenal glands, and eyes [16].

Many case reports indicate that $\mathrm{S}$. mansoni and $\mathrm{S}$. japonicum may affect the genital tract [17]. However, only two community-based studies have explored this via biopsy of the uterine cervix [18]. Both studies were carried out in low-endemic areas, and further investigations are required. Blood vessel anastomoses between the pelvic organs are probably responsible for 'spill-over' of eggs into the genital tract, and the cervix has been suggested to be the predilection site for trapped eggs [19]. In clinical practice, the cervix, the Fallopian tubes, and the vagina are the most common gynecological sites found to contain Schistosoma eggs [20, 21].

Genital schistosomiasis is associated with stress incontinence and increased frequency of urination. There are case reports of severe acute disease such as ascites with ovarian schistosomiasis, ectopic pregnancy, and heavy egg infestation of the uterus in pregnancy [22]. Several case reports indicate decreased fertility and abortions in women with FGS, but this has only been explored in two community-based studies and needs further investigation [23]. A direct effect on hormones or ovarian function is controversial [24]. It is likely that the women with fatal complications, such as extra-uterine pregnancies, may have died or recovered receiving neither diagnosis nor adequate care [12]. The largest study to date, in Zimbabwe, did not find any association between abortion or menstrual irregularities with $S$. haematobium. In Madagascar, however, an association was found with abortion. There are reports of soft cervices by bimanual palpation as usually found in pregnancy, although the clinicians in the community-based studies have not discussed this [25].

Case reports on girls below the age of 15 are very few and are most commonly from the vulval regions [25]. A vaginal polyp was found in a 3-year old [26], in the upper third of the vagina was found in a 16-year old [27], vulval lesion in a 9-year old [28], and in an 11-year old girl [29] were the handful of cases available after literature search. Furthermore, there are reports of stunting and late pubertal development, suggesting hormonal disturbances, confirmed in animal models with decreased fertility and arrested development of corpora lutea [30].

\section{Conclusion}

The widespread lack of awareness of genital schistosomiasis leads to misdiagnosis and therefore, false and ineffective therapy. As female genital schistosomiasis is rarely diagnosed correctly, knowledge about the effect of treatment is also scanty. Incorrect diagnostic of genital schistosomiasis lesions frequently leads to debilitating and irreversible operations such as ovarectomy, salpingotomiy and hysterectomy. It is therefore of utmost importance to sensitize health workers and raise awareness of urogenital schistosomiasis, particularly in endemic countries.

The public health advantages of anthelminthic treatment with praziquantel go beyond the simple benefits of curing schistosomiasis and preventing its related genital morbidity. Regardless of the presumptive causal association with HIV infection, urogenital schistosomiasis is a disabling disease by itself, and it should be prevented with the currently available means. The WHO recommended policy of regularly treating school-age children with praziquantel [30] should be reinforced and extended, to involve collaborations with programmes for preventing HIV and other sexually transmitted infections.

Competing Interests- Authors have declared that no competing interests exist.

Authors' Contributions- All authors contributed accordingly to this work

Consent- All authors declare that 'written informed consent was obtained from the patient (or other approved parties) for publication of this case report and accompanying images.

\section{Funding: Nil, Conflict of interest: Nil Permission from IRB: Yes}

\section{References}

1. Nour NM. Schistosomiasis: health effects on women.Rev Obstet Gynecol. 2010 Winter;3(1):28-32.

2. Schistosomiasis, Fact Sheet No 115; February 2010. World Health Organization. Available at http://www.who.int/mediacentre/factsheets/fs115/en/. Accessed: July 3, 2017. 


\section{Case Report}

3. Singh K, Muddasiru D, Singh J; Current status of schistosomiasis in Sokoto, Nigeria Parasite Epidemiology and Control, September 2016, Pages 239-244

4. Weekly epidemiological record 30 April No.18,2010, 85(32): 157-164. World health Organization. Available at www.who.int/wer/2010/wer8532/en/ Accessed: July 3,2017 .

5. Chistulo L, Loverde P, Engels D. Disease Watch: Schistosomiasis. TDR Nature Reviews Microbiology. 2004. 2:12-13

6. Feldmeier H, Krantz I, Poggensee G. Female genital schistosomiasis as a risk-factor for the transmission of HIV. Int J STD AIDS. 1994 Sep-Oct;5(5):368-72.

7. King $\mathrm{CH}$, Dangerfield-Cha $\mathrm{M}$. The unacknowledged impact of chronic schistosomiasis. Chronic Illn. 2008 Mar;4(1):65-79. doi: 10.1177/1742395307084407.

8. Kjetland EF, Ndhlovu PD, Gomo E, Mduluza T, Midzi $\mathrm{N}$, Gwanzura L, Mason PR, Sandvik L, Friis H, Gundersen SG. Association between genital schistosomiasis and HIV in rural Zimbabwean women. AIDS. 2006 Feb 28;20(4):593-600.

9. Secor WE, Shah A, Mwinzi PM, Ndenga BA, Watta CO, Karanja DM. Increased density of human immunodeficiency virus type 1 coreceptors CCR5 and CXCR4 on the surfaces of CD4+ $\mathrm{T}$ cells and monocytes of patients with Schistosoma mansoni infection. Infection and immunity. 2003 Nov 1;71(11):6668-71.

10. Siddappa NB, Hemashettar G, Shanmuganathan V, Semenya AA, Sweeney ED, Paul KS, Lee SJ, Secor WE, Ruprecht RM. Schistosoma mansoni enhances host susceptibility to mucosal but not intravenous challenge by R5 Clade C SHIV. PLoS Negl Trop Dis. 2011 Aug 2;5(8):e1270.

11. Tiboldi, T. Ovaries and adrenals in murine schistosomiasis mansoni. I. Histopathological changes of the ovaries in acute and chronic infection. Am. J. Trop. Med. Hyg. 1979; 28, 670-676

12. Kjetland EF, Kurewa EN, Mduluza T, Midzi N, Gomo E, Friis H, Gundersen SG, Ndhlovu PD. The first community-based report on the effect of genital Schistosoma haematobium infection on female fertility. Fertil Steril. 2010 Sep;94(4):1551-3. doi: 10.1016/j.fertnstert.2009.12.050. Epub 2010 Feb 10.

13. Petry KU, Scholz U, Hollwitz B, Von Wasielewski R, Meijer CJ. Human papillomavirus, coinfection with Schistosoma hematobium, and cervical neoplasia in rural
Tanzania. Int J Gynecol Cancer. 2003 Jul-Aug;13(4):5059.

14. North M, Dubinchik I, Hamid A, Elderiny S, Sayegh R. Association between cervical schistosomiasis and cervical cancer. A report of 2 cases. J Reprod Med. 2003 Dec;48(12):995-8.

15. Shadab HA, Chief Editor: Michael SB; schistosomiasis, emedicine.medscape, updated oct 2016, accessed 27th April 2017.

16. Poggensee G, Feldmeier H, Krantz I. Schistosomiasis of the female genital tract: public health aspects. Parasitology today. 1999 Sep 1;15(9):378-81.

17. Oliveira FA, Soares VL, Dacal AR, Cavalcante FG, Mesquita AM, Fraga F, Lang K, Feldmeier H. Absence of cervical schistosomiasis among women from two areas of north-eastern Brazil with endemic Schistosoma mansoni. Annals of Tropical Medicine \& Parasitology. 2006 Jan 1;100(1):49-54.

18. Qunhua L, Jiawen Z, Bozhao L, Zhilan P, Huijie Z, Shaoying $\mathrm{W}$, Delun $\mathrm{M}$, Hsu LN. Investigation of association between female genital tract diseases and Schistosomiasis japonica infection. Acta tropica. 2000 Nov 2;77(2):179-83.

19. Friedberg D, Berry AV, Schneider J. Schistosomiasis of the female genital tract. SAMJ. South African medical journal. 1991;80(3).

20. Swai B, Poggensee G, Mtweve S, Krantz I. Female genital schistosomiasis as an evidence of a neglected cause for reproductive ill-health: a retrospective histopathological study from Tanzania. BMC infectious diseases. 2006 Aug 23;6(1):134.

21. WHO, genital manifestation of schistosomiasis, a pocket atlas for clinical healthcare professionals 2017. Available www.who.int/schistosomiasis/genitalschistosomiasis/en/ , accessed $3^{\text {rd }}$ July, 2017.

22. Hoffmann, H. and Bauerfeind, I. High tissue egg burden mechanically impairing the tubal motility in genital schistosomiasis of the female. Acta Obstet. Gynecol. Scand. 2003; 82, 970-971

23. Leutscher P, Ravaoalimalala VE, Raharisolo C, Ramarokoto CE, Rasendramino M, Raobelison A, Vennervald B, Esterre P, Feldmeier H. Clinical findings in female genital schistosomiasis in Madagascar. Trop Med Int Health. 1998 Apr;3(4):327-32. 


\section{Case Report}

24. Kjetland EF, Kurewa EN, Ndhlovu PD, Midzi N, Gwanzura L, Mason PR, Gomo E, Sandvik L, Mduluza T, Friis H, Gundersen SG. Female genital schistosomiasis-a differential diagnosis to sexually transmitted disease: genital itch and vaginal discharge as indicators of genital Schistosoma haematobium morbidity in a cross-sectional study in endemic rural Zimbabwe. Tropical Medicine \& International Health. 2008 Dec 1;13(12):1509-17.

25. Charlewood GP, Shippel S, Renton H. Schistosomiasis in gynaecology. J Obstet Gynaecol Br Emp. 1949 Jun;56(3):367-85.

26. Al-Adnani MS, Saleh KM. Extraurinary schistosomiasis in Southern Iraq. Histopathology. 1982 Nov;6(6):747-52.
27. Bellingham FR. Genital bilharzia: a report of 3 cases. Aust N Z J Obstet Gynaecol. 1972 Nov;12(4):267-8.

28. Savioli L, Gabrielli A, Neve H. Vulvar Schistosoma haematobium lesion treated with praziquantel. Tropical doctor. 1990;20(1):45-6.

29. O'Mahony D, Banach L, La Grange LL. A case of vulval schistosomiasis. South African Family Practice. 2007;49(9):42-3.

30. Kjetland EF, Leutscher PD, Ndhlovu PD. A review of female genital schistosomiasis. Trends Parasitol. 2012 Feb;28(2):58-65. doi: 10.1016/j.pt.2011.10.008. Epub 2012 Jan 12.

\section{How to cite this article?}

S. M. Sahabi, A. F. Rabiu. Unusual presentation of schistosomiasis as vulval polyp. Obs Rev:J obstet Gynecol 2017;3(4):3337.doi:10.17511/joog.2017.i04.01. 